\title{
Synthesis and Characterization of Ferric Sorbate and Aluminum Sorbate as Antifouling Pigments for Marine Paints
}

\author{
Miriam Pérez, ${ }^{\dagger \dagger}$ Mónica García, ${ }^{\dagger}$ Mirta Stupak, $^{\dagger}$ and Guillermo Blustein $*, \dagger, \S$ \\ ${ }^{\dagger}$ Centro de Investigación y Desarrollo en Tecnología de Pinturas, CIDEPINT, 52 e/121 y 122, La Plata, Argentina \\ ${ }^{\ddagger}$ Facultad de Ciencias Naturales y Museo and ${ }^{\S}$ Facultad de Ciencias Agrarias y Forestales, Universidad Nacional de La Plata, La Plata, \\ Buenos Aires, Argentina
}

\begin{abstract}
Biofouling is a natural process that involves the settlement and growth of organisms on natural or man-made structures and leads to material deterioration, generating severe technical and economic problems. The use of paints has been a practical method to control marine biofouling. However, some biocides currently employed have been banned because of their toxicity. There is a growing need for environmentally safe antifouling systems. The current study describes the synthesis and characterization of two new pigments, ferric sorbate and aluminum sorbate, as potential antifoulants. Laboratory assays with fouling organisms and field trials with antifouling paints were conducted. The antifouling activity of sorbate-pigment-based paints was successful and could be attributed to the combined action of a sorbate anion and low $\mathrm{pH}$ values generated by hydrolysis at the paint/seawater interface. After 9 months of exposure in the sea, paints containing synthetic sorbate salts had much lower fouling settlement compared to controls, indicating that these pigments are promising candidates for biofouling control.
\end{abstract}

\section{INTRODUCTION}

Engineered structures emplaced in the marine environment, such as oil-drilling platforms, weather stations, navigation buoys, marine farms, ships and jetties, are constantly threatened by saltwater, temperature fluctuations, and biological colonization. ${ }^{1}$ Biofouling is a natural process that involves the settlement and growth of micro- and macroorganisms onto any submerged hard substrate, whether natural or artificial. ${ }^{2}$ The development of marine biofouling on a submerged surface is a fast and sequential process that involves four general steps 3,4 (Figure 1). The first event includes the accumulation of an

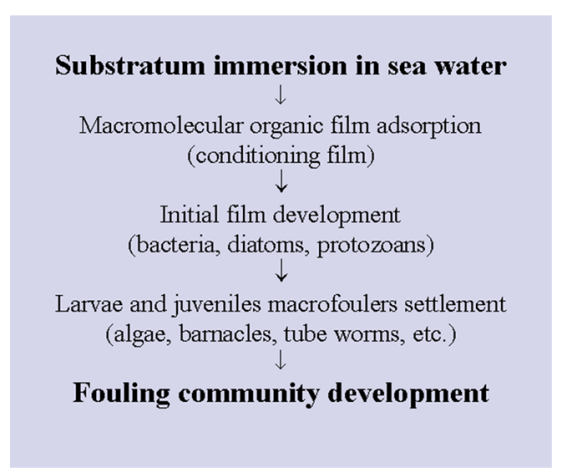

Figure 1. Stages of attachment of marine organisms on surfaces immersed in seawater.

organic conditioning film consisting of protein, proteoglycans, and polysaccharides, making the surface wettable. After approximately $1-2 \mathrm{~h}$, colonization of bacteria occurs involving two distinct phases, a reversible approach phase ("adsorption") and a nonreversible attachment phase ("adhesion"). ${ }^{5}$ Bacteria secrete extracellular polymeric substances, and with other colonizing microorganisms as diatoms, spores of macroalgae and protozoans constitute the so-called biofilm or primary film. ${ }^{6}$ Finally, a great diversity of larvae of marine macrofoulers (hydroids, barnacles, mussels, tube worms, and tunicates) arrives.

Biofouling settlement leads to the deterioration of underwater man-made structures and generates severe technical and economic problems. In particular, these undesirable effects are important in the aquaculture industry and on oil-drilling platforms and ship hulls. ${ }^{7}$ The problems associated with biofouling in aquaculture comprise fouling on infrastructure (immersed structures, such as cages, netting, and pontoons) and stock species (farmed species, particularly shellfish, such as mussels, scallops, and oysters). Besides, marine biofouling modifies the hydrodynamics of ship hulls and consequently increases fuel consumption, promotes corrosion processes, reduces heat-transfer performance on heat exchangers, and causes serious problems on cooling systems for power plants. Another consequence of fouling on ships is the hull transport and/or ballast water and spread of invasive species, which may lead to the exclusion or displacement of native plant and animal species by competition for food, light, and space. ${ }^{8}$

The use of paints on ship hulls has been a practical method to control marine biofouling. However, biocides currently employed in paint formulations, such as lead, arsenic, mercury, tin, and their organic derivatives (TBT and TBTO), have been banned by the International Maritime Organization because they are harmful for human beings and the environment. Even though antifouling paints remain the best option for biofouling control, many formulations still contain toxic compounds, such as cuprous oxide ${ }^{9}$ and other controversial organic compounds. ${ }^{4,10,11}$ As a consequence, there is a growing need for

Received: November 18, 2013

Revised: January 17, 2014

Accepted: February 16, 2014

Published: February 16, 2014 
environmentally safe antifouling systems. Some marine organisms, such as corals, algae, sponges, and ascidians, have been shown to produce antifouling substances, which in nature keeps them free of undesirable encrusting organisms. ${ }^{12,13}$ However, to date, most of these antifouling metabolites have been isolated in low yields from delicate and slow-growing marine organisms, which cannot be harvested on a commercial scale without environmental harm. ${ }^{14}$ For this reason, the search for environmentally friendly antifoulants should be directed toward another source of more sustainable nontoxic compounds.

In a previous study, ${ }^{15}$ it was demonstrated that potassium sorbate, a short-chain unsaturated fatty acid, is a promising antifouling compound. Fatty acids are natural metabolites that occur in a wide variety of organisms and have both antimicrobial and antifouling properties. ${ }^{16-18}$

Potassium sorbate is a salt of $(E, E)-2,4$-hexadienoic acid that is used widely as a food preservative to inhibit the growth of bacteria, mold, yeasts, and fungi (Figure 2). This compound is a

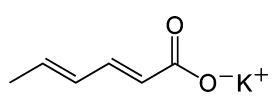

Figure 2. Potassium sorbate structure.

cheap and biodegradable commercial chemical classified as "generally regarded as safe" by the U.S. Food and Drug Administration. ${ }^{19,20}$ Potassium sorbate showed good antisettlement activity at concentrations that were not acutely toxic to barnacle larvae (therapeutic ratio $=3.71$ ), and the effect was reversible, demonstrating that the compound acts via a nontoxic mechanism. ${ }^{15}$

Potassium sorbate is highly soluble in water. Moreover, the use of water-soluble compounds could promote the osmotic blistering of the coating when they are submerged in seawater. Further, the soluble antifoulants are quickly leached from the paint film by water penetrating the pores of the coating. As a whole, these facts lead to premature deterioration of the paint films with concomitant loss of antifouling activity. However, it is possible to encapsulate soluble compounds ${ }^{21}$ to prolong the lifetime of paint or to prepare less-soluble sorbates with certain metallic cations to be used as antifouling pigments.

The current study describes the laboratory preparation and characterization of two new pigments, ferric sorbate and aluminum sorbate. The antifouling activity of these pigments was checked by laboratory toxicity tests on two common species of the fouling community at Mar del Plata harbor, Balanus amphitrite (Cirripedia, Balanidae) and Polydora sp. (Polychaeta, Spionidae). Also, field trials employing Phytagel disks and antifouling paints are presented.

\section{EXPERIMENTAL SECTION}

Pigment Preparation and Characterization. Two pigments as potential antifoulants were prepared in the laboratory, ferric sorbate (FeSor) and aluminum sorbate (AlSor). In both cases, a $0.33 \mathrm{M}$ metallic $\left(\mathrm{Fe}^{3+}\right.$ or $\mathrm{Al}^{3+}$ ) nitrate solution was dropped into a beaker containing a $1 \mathrm{M}$ potassium sorbate solution, under continuous stirring. Once the addition of metallic nitrate was completed, the solution was gently stirred for $1 \mathrm{~h}$. The precipitate was washed three times with a $10^{-3} \mathrm{M}$ potassium sorbate solution to avoid hydrolysis; the supernatant liquid was then decanted, and the solid was filtered off by means of a Büchner funnel. Finally, the precipitate was first dried at room temperature and then under reduced pressure to completely remove the remaining wetness.

The composition of the sorbate pigments was determined in order to establish their stoichiometric formulas. The iron, aluminum, and sorbate were analyzed in an independent way.

Samples of sorbate pigments were dissolved in hydrochloride acid because in this media cations remain soluble while sorbic acid separates as a solid. Then, sorbic acid was redissolved and diluted in alkaline media and determined directly by highperformance liquid chromatorgraphy (HPLC). The chromatographic analyses were carried out in a Shimadzu highperformance liquid chromatograph (Shimadzu Corp., Kyoto, Japan) equipped with two LC-10AS pumps, a CTO-10A column oven, a 7725 Rheodyne manual injector (Cotati, CA), and a model SPD-10A variable-wavelength UV-vis detector using a SCL-10A system controller module and a C-R7A chromatopac integrator. The quantitative HPLC separations were performed at a temperature of $30{ }^{\circ} \mathrm{C}$ (controlled by the oven) on a LiChrospher $100 \mathrm{RP}-18,125 \times 4 \mathrm{~mm}, 5 \mu \mathrm{m}$ particle size, reversed-phase column (Merck). The mobile phase was a $0.5 \mathrm{~g} / \mathrm{L}$ sodium acetate solution $(\mathrm{pH} 4.3)$. The flow rate was 1 $\mathrm{mL} / \mathrm{min}$, and the absorbance detector was set at $238 \mathrm{~nm}$.

Both metallic cations were determined by indirect gravimetry, i.e., weighing an aliquot of the pigment into a crucible and then burning it at $1100{ }^{\circ} \mathrm{C}$.

In order to evaluate the contamination grade of the prepared pigments, the nitrate and potassium ions were measured. The potassium content was determined by atomic absorption spectrophotometry, and the nitrate anion was potentiometrically quantified using an ion-selective electrode.

The physicochemical characteristics of pigments, such as the $\mathrm{pH}$ and solubility, in artificial seawater were also determined at room temperature. For this, saturated solutions were obtained as follows: $10 \mathrm{~g}$ of sorbate pigments were incorporated into a glass beaker containing $1000 \mathrm{~mL}$ of artificial seawater. Then, the suspensions were stirred for $24 \mathrm{~h}$ to achieve the equilibrium solubility. Finally, saturated solutions were obtained from the suspensions by filtration employing a Büchner funnel. The sorbate concentration of the saturated solution was measured by HPLC as described above, and the $\mathrm{pH}$ was determined with a benchtop $\mathrm{pH}$ meter.

Laboratory Bioassays. Bioassays were performed using larvae of B. amphitrite and Polydora sp., two common species of the fouling community at Mar del Plata harbor, Argentina $\left(38^{\circ}\right.$ $08^{\prime} 17^{\prime \prime} \mathrm{S}$ and $\left.57^{\circ} 31^{\prime} 18^{\prime \prime} \mathrm{W}\right)$. B. amphitrite adults were collected from Club de Motonáutica piers, and Polydora sp. larvae were obtained with a $25 \mu \mathrm{m}$ zooplankton net at the site. In the laboratory, all organisms were conditioned in artificial seawater (ASTM D1141/75, $\mathrm{pH} 8.2$ ) at $20 \pm 1{ }^{\circ} \mathrm{C}$ with suitable aeration and natural light. Adult barnacles were fed a daily diet of Artemia salina nauplii and Polydora sp. larvae with cultures of the diatom Skeletonema costatum. Newly released B. amphitrite larvae (nauplii I) were transferred to a beaker containing filtered seawater; they molted and became nauplii II approximately $1 \mathrm{~h}$ after release. Some nauplii II actively swimming toward a light source were selected for bioassays.

For the experiments, $1 / 2,1 / 4,1 / 8,1 / 16,1 / 32$, and $1 / 64$ dilutions from saturated solutions of FeSor and AlSor were prepared. Before the bioassays were performed, some dilutions were buffered in order to fit their $\mathrm{pH}$ value close to the artificial seawater value, i.e., 8.1-8.2. A total of 30 nauplii II of $B$. amphitrite and 30 larvae of Polydora sp. (15-16 setigerous stage, i.e., close to the tube-forming stage) were used for the 
toxicity assays. Larvae were added using a Pasteur pipet to small crystallizing dishes containing $50 \mathrm{~mL}$ of testing solutions. A 50 inactivity time $\left(\mathrm{It}_{50}\right)$ was estimated, i.e., the time required for $50 \%$ of the test organisms to become inactive for each concentration. $^{22}$ The inability of larvae to stay in the water column and the loss of a phototactic reaction were scored as toxic responses. ${ }^{23}$

All bioassays were carried out with three replicates of each treatment and repeated twice with separate batches of larvae. In all cases, the experiments were compared with the controls (filtered artificial seawater).

In the laboratory, toxic compounds are not differentiated from narcotic compounds, and for this reason, larvae were placed in seawater to determine if they recovered. In order to detect if the effect of compounds on larvae was temporary (narcotic) or permanent (toxic), refreshing experiments were also carried out. For the experiments, larvae exposed to solutions were removed and placed in vessels with clean artificial seawater. Then, the percentage of larval recovery was estimated.

Field Trials. Phytagel Assays. Phytagel disks were exposed in the sea for 28 days during summer months (December to March) when the highest peak of recruitment of fouling species occurs. 4,24

The procedure for immobilization of pigments into the gel was adapted from that described in the literature. ${ }^{25}$ Gels were made by dissolution of $7.2 \mathrm{~g}$ of Phytagel (Sigma Chemical) in $180 \mathrm{~mL}$ of distilled water in a microwave oven. After cooling at $50{ }^{\circ} \mathrm{C}, 0.1 \mathrm{~g}$ of each sorbate pigment suspended in $10 \mathrm{~mL}$ of distilled water was incorporated into the gel matrix with vigorous stirring. The gel/pigment mixtures were poured into polystyrene Petri dishes ( $9 \mathrm{~cm}$ diameter) containing a nylon mesh to reinforce the structural integrity and to prevent detachment of gel. Likewise, gels without any compound added were used as controls. Petri dishes were placed on rectangular aluminum structures and hung from the marina at $50 \mathrm{~cm}$ below the water line for 28 days. Results from gels were used as a screening test in order to establish whether sorbate pigments might be adequate to be included in antifouling paint formulations.

Tests were carried out in triplicate. The settlement of fouling organisms was estimated as the percentage cover on each gel using a dot-grid estimate method. ${ }^{26}$

Antifouling Paints. Soluble matrix paints were formulated with colophony as the film-forming material and oleic acid as the plasticizer. Colophony is a brittle solid (glass transition temperature of about $30{ }^{\circ} \mathrm{C}$ ) obtained from exudation of pine and fir trees. Water white rosin is the common variety used to formulate antifouling paints, which contain abietic acid as the main component ${ }^{27}$ (Figure 3).

In all cases, sorbates were incorporated as antifouling pigments and calcium carbonate was added to complete the pigment formula. The pigment volume concentration was $37 \%$.

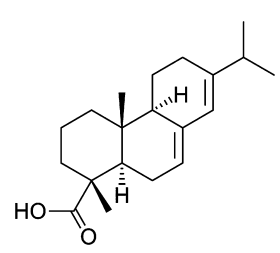

Figure 3. Abietic acid structure.
The composition of this paint, expressed as volume percentages, was as follows: $37.6 \%$ colophony, $6.8 \%$ oleic acid, $27.3 \%$ xylene/white spirit, $4.1 \%$ calcium carbonate, and $24.2 \%$ sorbate pigments.

The procedure for preparation of the paint involves three stages. First of all, rosin and oleic acid are dissolved in a mixture of solvents to obtain the "vehicle". Then, a ball mill is loaded with vehicle + pigments and dispersed for $24 \mathrm{~h}$. After that, paints are filtered through a Lycra grid in order to eliminate environmental dust and/or bigger particles.

Paints were applied to sandblasted acrylic panels $\left(128 \mathrm{~cm}^{2}\right)$ with a paint brush to reach a dry-film thickness of $100 \pm 5 \mu \mathrm{m}$. A series of unpainted panels were used as controls to establish fouling community development. All panels were placed on rectangular aluminum structures and submerged in a marina in Mar del Plata harbor at $50 \mathrm{~cm}$ below the water line. Painted and unpainted panels were evaluated after 3, 6, and 9 months. All tests were performed in triplicate.

After exposure in the sea, abundance percentages for each species of fouling settled on panels were estimated using a dotgrid method. ${ }^{26}$

Statistical Analysis. All statistical analyses were performed with Statistica 8.0. The normality assumption was verified with the Shapiro-Wilk test. ${ }^{28}$ The differences between treatments and controls were determined by one-way analysis of variance, followed by the Tukey posthoc test. The differences were considered to be significant at $p<0.05$.

\section{RESULTS AND DISCUSSION}

Pigment Characterization. The composition of FeSor was $14.3 \%$ iron, $84.9 \%$ sorbate, $0.02 \%$ potassium, and $0.01 \%$ nitrate. The AlSor composition was $7.5 \%$ aluminum, $92.3 \%$ sorbate, 0 , $03 \%$ potassium, and $0.01 \%$ nitrate. Analysis of these results revealed that there was $3 \mathrm{~mol}$ of sorbate $\left(\mathrm{C}_{6} \mathrm{H}_{7} \mathrm{O}_{2}\right)$ per each 1 mol of metallic cation; then, it was concluded that the stoichiometric relationship for metallic laboratory-prepared pigments was $\mathrm{Fe}\left(\mathrm{C}_{6} \mathrm{H}_{7} \mathrm{O}_{2}\right)_{3}$ and $\mathrm{Al}\left(\mathrm{C}_{6} \mathrm{H}_{7} \mathrm{O}_{2}\right)_{3}$, respectively.

Pigment precipitation could be described as follows:

$$
\begin{aligned}
& 3 \mathrm{C}_{6} \mathrm{H}_{7} \mathrm{O}_{2}^{-}+\mathrm{Fe}^{3+} \leftrightarrow \mathrm{Fe}\left(\mathrm{C}_{6} \mathrm{H}_{7} \mathrm{O}_{2}\right)_{3} \downarrow \\
& 3 \mathrm{C}_{6} \mathrm{H}_{7} \mathrm{O}_{2}^{-}+\mathrm{Al}^{3+} \leftrightarrow \mathrm{Al}\left(\mathrm{C}_{6} \mathrm{H}_{7} \mathrm{O}_{2}\right)_{3} \downarrow
\end{aligned}
$$

It is important to remark that the methodology employed to prepare these pigments at laboratory scale is quite simple and, perhaps, it could be industrially scaled. Moreover, the pigment composition is highly reproducible when prepared and run under the same conditions. Additionally, raw materials employed in this process are cheap industrial products that are commercially available in the market.

The experimental solubilities of pigments in seawater were $64 \mathrm{mg} / 100 \mathrm{~mL}$ and $151 \mathrm{mg} / 100 \mathrm{~mL}$ for FeSor and AlSor, respectively. Otherwise, the solubility of potassium sorbate was close to $60 \mathrm{~g} / 100 \mathrm{~mL}$, i.e., 3 orders of magnitude larger than those of FeSor and AlSor pigments, and consequently this compound result is inappropriate for antifouling formulations. Conversely, the solubility values obtained for FeSor and AlSor pigments showed that they were suitable for inclusion in antifouling coatings. ${ }^{29-32}$

The $\mathrm{pH}$ values of the pigment suspensions were around 3.73.8 , suggesting that when they were suspended in seawater, hydrolysis reactions took place. 


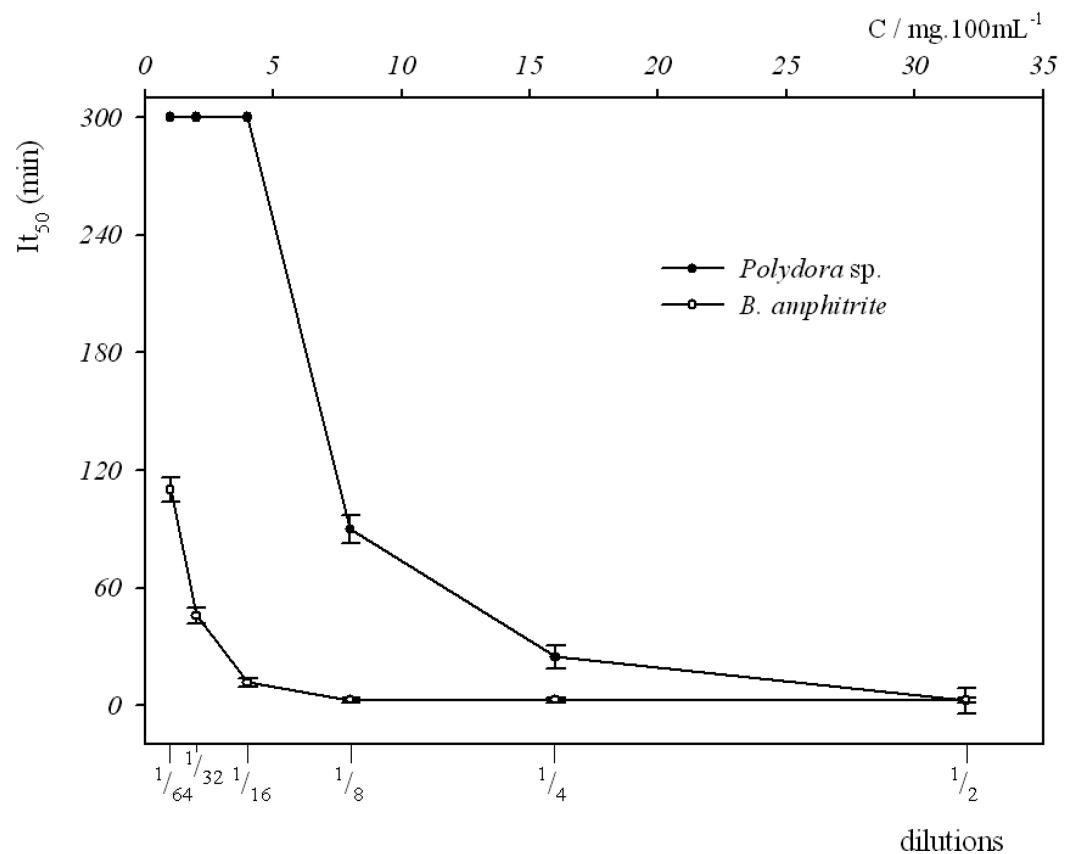

Figure 4. Larval $\mathrm{It}_{50}$ versus FeSor solutions.

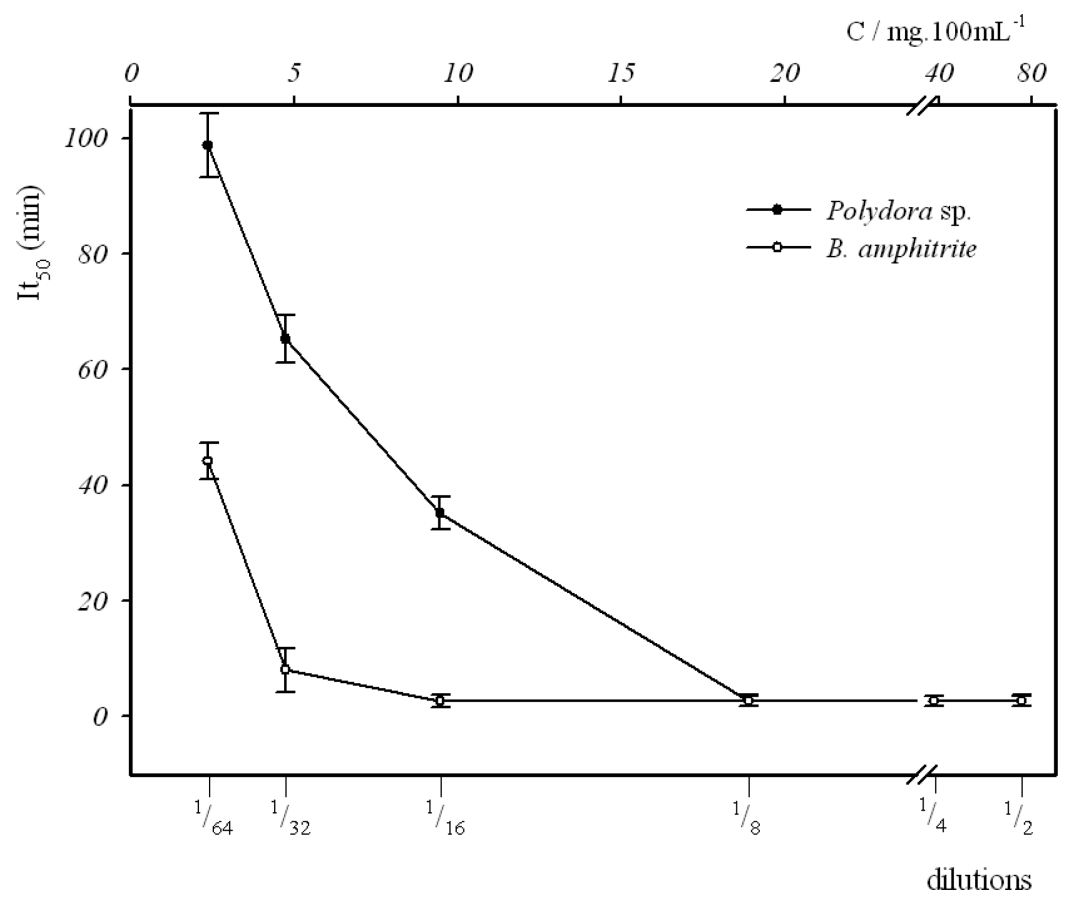

Figure 5. Larval $\mathrm{It}_{50}$ versus AlSor solutions.

$$
\begin{aligned}
& \mathrm{M}\left(\mathrm{C}_{6} \mathrm{H}_{7} \mathrm{O}_{2}\right)_{3}+n \mathrm{HCO}_{3}^{-} \\
& \quad \leftrightarrow \mathrm{M}\left(\mathrm{C}_{6} \mathrm{H}_{7} \mathrm{O}_{2}\right)_{3-n} \mathrm{OH}_{n}+\mathrm{CO}_{2}+\mathrm{C}_{6} \mathrm{H}_{7} \mathrm{O}_{2}^{-}
\end{aligned}
$$

where $\mathrm{M}=\mathrm{Fe}^{3+}$ or $\mathrm{Al}^{3+}$. Then, the basic sorbate reacts with water to give sorbic acid:

$$
\begin{aligned}
& \mathrm{M}\left(\mathrm{C}_{6} \mathrm{H}_{7} \mathrm{O}_{2}\right)_{3-n} \mathrm{OH}+m \mathrm{H}_{2} \mathrm{O} \\
& \quad \leftrightarrow \mathrm{M}\left(\mathrm{C}_{6} \mathrm{H}_{7} \mathrm{O}_{2}\right)_{3-n-m} \mathrm{OH}_{n+m}+n \mathrm{C}_{5} \mathrm{H}_{7} \mathrm{COOH}
\end{aligned}
$$

When enough sorbate pigment is available in the suspension, hydrolysis may proceed and eventually metallic hydroxides and sorbic acid could be formed. In fact, reaction (4) is responsible of the $\mathrm{pH}$ measured in the aqueous extract and especially at the paint/seawater interface. ${ }^{33}$ The natural buffering system of seawater becomes highly inadequate for marine life when a large amount of acids or alkaline substances are added. Most of the organisms grow and complete their life cycles in a narrow range of $\mathrm{pH}$. For this reason, laboratory bioassays were carried out, neutralizing the $\mathrm{pH}$ of the test solutions close to the artificial seawater value. In contrast, the hydrolytic acidity afforded by the pigments at the paint/seawater interface could be a powerful tool to develop an environmentally safe antifouling system. ${ }^{32}$ 


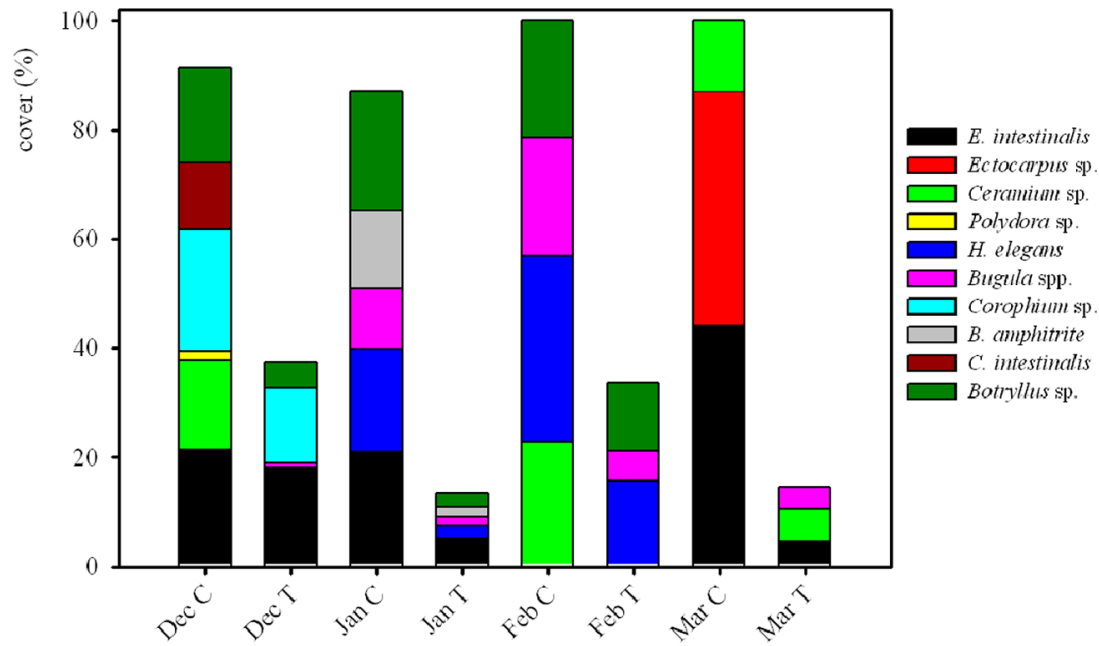

Figure 6. Fouling cover percentage on gel disks [C, control; T, treatments (FeSor)].

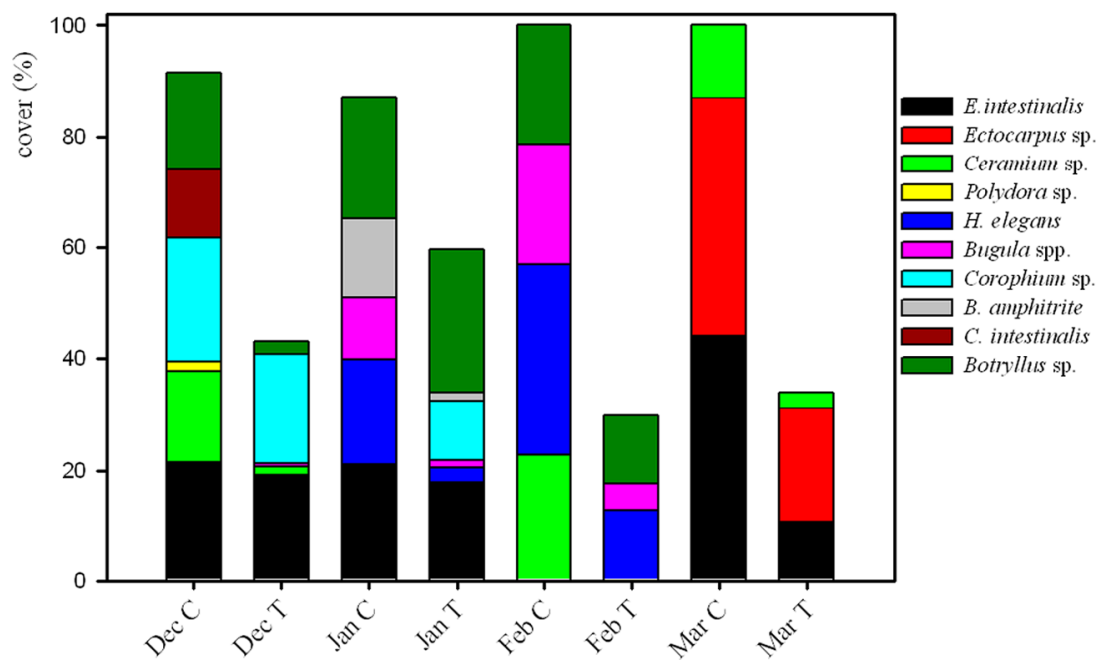

Figure 7. Fouling cover percentage on gel disks [C, control; T, treatments (AlSor)].

Laboratory Assays. Larval Toxicity Test. Laboratory tests were conducted using larvae exposed to increasing concentrations of FeSor and AlSor solutions in seawater (Figures 4 and 5).

The toxicity test showed that nauplii II of B. amphitrite and 15-16 setigerous larvae of Polydora sp. were affected in a similar way by solutions of sorbate pigments; i.e., larvae responded with a loss of phototactic response, and they became immediately quiescent, immobilized their appendages, and stopped their swimming movements. However, it is important to note that barnacle nauplii were more sensitive than Polydora sp. to both sorbate solutions, even from the lowest concentrations (i.e., 1/64 dilution). A comparison of both sorbate solution curves demonstrated that AlSor affected the larval activity more rapidly than FeSor. In all cases, the inhibitory response was in a concentration-dependent manner.

$\mathrm{It}_{50}$ experimentally determined for $B$. amphitrite nauplii exposed to sorbate solutions was similar to that obtained in SCNCu solutions. ${ }^{34}$ From an environmental point of view, these results represent an advantage because a satisfactory antifouling effect was reached with copper-free pigments.

After $24 \mathrm{~h}$ of exposition, nauplii and Polydora sp. larvae were transferred to fresh artificial seawater and the percentage recovery was estimated. In all concentrations, all larvae recovered swimming movements and were able to complete their development; that is to say, sorbate compounds have a temporary effect. Reversible antifouling activity, meaning that larvae can settle normally after leaving the environment containing the antifouling substance, is a direct measure and evidence for nontoxicity of compounds. However, it has only been experimentally proven for a few compounds. ${ }^{15,35}$

Field Trials. Phytagel Assays. The development of effective antifouling coatings requires field trials. Field antifouling assays are more ecologically relevant and more sensitive to detection of the activity spectrum of antifouling substances. ${ }^{36}$

From the beginning of the summer, both sorbate pigments were capable of inhibiting the settlement of a broad range of fouling organisms in field experiments.

After 28 days of exposure in December, marked inhibition on the settlement of the red algae Ceramium sp., the sand tube building polychaete Polydora sp., and the solitary ascidian Ciona intestinalis was recorded for both FeSor and AlSor $(p<0.05)$. However, attachment of the common green algae Enteromorpha intestinalis was no affected by these compounds.

The most relevant results obtained from January and February on sorbate gels were the strong inhibition of calcareous species, particularly B. amphitrite and Hydroides elegans. Also, significant differences on the settlement of the 
(a)

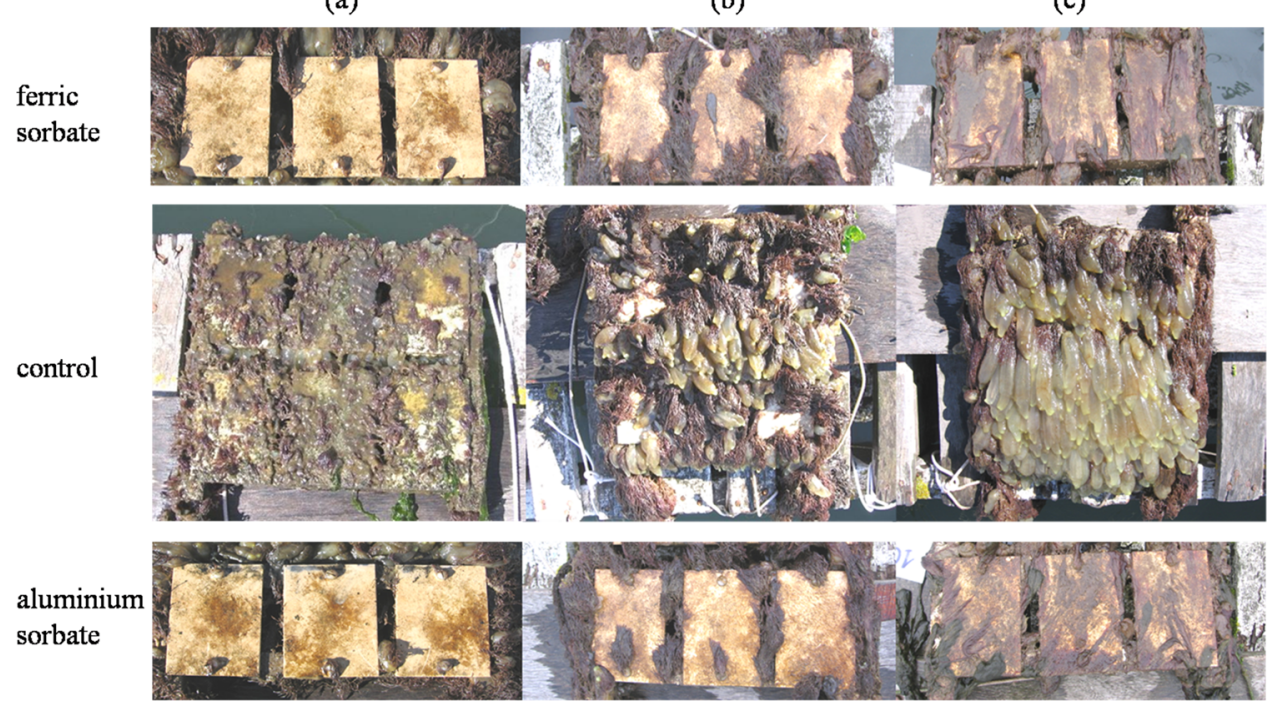

Figure 8. Panels immersed at Mar del Plata harbor: (a) 3 months; (b) 6 months; (c) 9 months.

arborescent bryozoan Bugula neritina were observed. A particular case was registered for the colonial ascidian Botryllus sp. because it was virtually absent in all replicas except on January gel disks when settled at a similar percentage as the control. Results from February samples indicated that the percentage of larval settlement of $H$. elegans and B. neritina on treated gel disks was significantly lower than that of a control disk; also, the complete absence of algal species, Polydora sp. and $B$. amphitrite was detected $(p<0.05)$.

In late summer (March gel disks), the recruitment of species drastically diminished and the fouling community was dominated by seaweeds. Both FeSor and AlSor maintained their antifouling activity and affected algal settlement (Figures 6 and 7 ).

Unlike the majority of recently reported antifouling compounds, FeSor and AlSor are effective against multiple species in Phytagel assays. This characteristic gives sorbates the potential to achieve a better performance on the broad spectrum of fouling organisms and encourages their incorporation in marine coatings.

Antifouling Paints. Antifouling coatings are film-forming products that act as controlled release vehicles of antifoulants. A reasonable number of active antifouling compounds have already been identified from different sources, but only a few included in a paint formulation have been studied. Laboratory preparation and evaluation of antifouling paints in the sea represent a stage in fouling control research that is not usually carried out.

After 9 months of exposure in the sea, paints containing FeSor or AlSor had much lower fouling settlement compared to that of controls, indicating that these compounds were strongly resistant to biofouling of Mar del Plata harbor. This performance was observed from the first and second samplings after 3 and 6 months of immersion, respectively.

FeSor and AlSor pigments released from the paint produced an inhibitive microlayer at the paint surface/seawater interface that deters the settlement of microscopic larvae or spores of fouling organisms. Only a thin slime composed of some diatoms (Melosira, Achnanthes, and Grammatophora) and protozoans (Vorticella) was observed on the paint surface. In contrast, control panels were heavily invaded by microfouling species, seaweeds (E. intestinalis and Ceramium sp.), and other macrofouling organisms (mainly Polydora sp., Bugula, C. intestinalis, and Botryllus sp.; Figure 8; $p<0.05$ ). This is consistent with previous studies that established strong inhibition of the sorbate anion included in a varnish on both microfouling (particularly diatoms) and macrofouling species (mainly E. intestinalis, Ectocarpus sp., B. amphitrite, Bugula spp., C. intestinalis, and Botryllus spp.). ${ }^{15}$

Several controlled-release films with soluble sorbates (e.g., sorbic acid and potassium sorbate) have been studied in order to develop antimicrobial materials for the food-packaging industry. The film-forming materials most frequently used for active packages include natural ${ }^{37,38}$ (e.g., shrimp chitosan, cornstarch) and synthetic organic polymers ${ }^{39-41}$ [poly(ethylene-co-methacrylic acid), cellulose acetate, epoxy-poly(vinylpyrrolidone)] as well as hybrid polymers ${ }^{42}$ [poly(vinyl alcohol) + bacterial cellulose]. Additionally, antimicrobial inorganic silica films obtained via a sol-gel technique were also reported. ${ }^{43}$ However, this is the first report on the use of FeSor or AlSor for coatings, particularly in antifouling paints.

The performance of sorbate-pigment-based paints, with regard to their antifouling activity, could be attributed to the combined action of at least two factors: the sorbate anion and $\mathrm{pH}$.

It was well established that the $\mathrm{pH}$ of the environment could affect the growth and development of a wide variety of organisms. The $\mathrm{pH}$ of the world's oceans remains relatively constant at $\mathrm{pH} 8.2$, but that of estuaries and freshwater bodies can vary extensively from one location or season to another. ${ }^{44,45}$ In the case of antifouling paints, the $\mathrm{pH}$ of the boundary layer in which antifoulants function will be moderated by the type of paint matrix and by compounds leaching from the paint. In this sense, sorbate pigments hydrolyze, decreasing the $\mathrm{pH}$ value at the paint/seawater interface in a way similar to that of other antifouling pigments, such as ferric benzoate. ${ }^{33}$

The activity of many organic biocides is affected by changes in the $\mathrm{pH}$, especially those that ionize. Weak acids tend to become more toxic at low $\mathrm{pH}$ values, while the toxicity of basic biocides is increased with increasing $\mathrm{pH}^{46}$ These mechanisms directly affect the development and growth of organisms and 
are responsible of antifouling action. Altering the environmental $\mathrm{pH}$ can cause changes in the cell physiology, such as charge distribution on bacterial cell walls, and consequently affect the uptake of charged biocides. ${ }^{47}$

Depending on the $\mathrm{pH}$ of the environment, sorbate in solution exists in equilibrium between the dissociated state (sorbate anion) and the undissociated state (sorbic acid). As shown in eqs 3 and 4, the formation of sorbic acid is favored during the progress of hydrolysis of the sorbate pigments. Sorbic acid is a neutral compound that is lipid-permeable and is able to diffuse into the cell, reaching equilibrium when the inside and outside concentrations of sorbic acid are equal. Inside, a new equilibrium is formed between sorbic acid and sorbate, releasing protons into the cytoplasm and causing inhibition of many metabolic functions. ${ }^{48}$ Furthermore, the lipophilic tail of the sorbate molecule has been shown to disrupt the membrane and interfere with membrane proteins. ${ }^{49}$

The role of fatty acids on the larval settlement is controversial. Some authors theorize that fatty acids such as palmitoleic, linoleic (18:2), arachidonic (20:4), and eicosapentaenoic acids induce larval settlement though low percentages of metamorphosis. ${ }^{50}$ However, experiments on the polychaete Capitella sp. demonstrated that linoleic acid and eicosatrienoic acid induced larval settlement and metamorphosis in this worm. ${ }^{51}$ In contrast, studies confirm that a branched-chain fatty acid produced by a marine bacterium isolated from deep-sea sediment effectively inhibited the larval settlement of biofouling polychaete $H$. elegans. ${ }^{16}$

The present study provides evidence that synthetic sorbate salts, such as FeSor and AlSor, can effectively prevent fouling either in the laboratory or in more ecologically realistic field assays. An ideal antifouling compound should be repellent at the paint surface but harmless in the surrounding environment. Overall, this investigation demonstrates that sorbates can act as antifouling agents in a nontoxic manner. These compounds also have the advantage that they can be easily manufactured and thus have lower cost for commercial use. For these reasons, FeSor and AlSor are promising candidates for antifouling technology.

\section{AUTHOR INFORMATION}

\section{Corresponding Author}

*E-mail: antifouling@cidepint.gov.ar.

\section{Notes}

The authors declare no competing financial interest.

\section{ACKNOWLEDGMENTS}

The authors thank the Agencia Nacional de Promoción Cientifica y Tecnológica (ANPCyT), Consejo Nacional de Investigaciones Cientificas y Técnicas (CONICET), Comisión de Investigaciones Científicas de la provincia de Buenos Aires (CICPBA), Universidad Nacional de La Plata (Argentina), and Universidad de Buenos Aires for their economical support. The authors thank Claudio Cerruti for HPLC measurements. They also thank the Club de Motonáutica of Mar del Plata for permission to use their marine testing site.

\section{REFERENCES}

(1) Chambers, L.; Stokes, K.; Walsh, F.; Wood, R. Modern approaches to marine antifouling coatings. Surf. Coat. Technol. 2006, 201, 3642 .

(2) Evans, L.; Hoagland, K. Algal biofouling; Elsevier: Amsterdam, The Netherlands, 1986.
(3) Railkin, A. Marine Biofouling: Colonization Processes and Defenses; CRC Press: Boca Raton, FL, 2004.

(4) Yebra, D.; Kiil, S.; Dam-Johansen, K. Antifouling technology-past, present and future steps towards efficient and environmentally friendly antifouling coatings. Prog. Org. Coat. 2004, 50, 75.

(5) Callow, M.; Fletcher, R. The influence of low surface energy materials on bioadhesion: a review. Int. Biodeterior. Biodegrad. 1994, 34, 333.

(6) Wahl, M. Marine epibiosis. I. Fouling and antifouling: some basic aspects. Mar. Ecol.: Prog. Ser. 1989, 58, 175.

(7) Armstrong, E.; Boyd, K.; Burgess, J. Prevention of marine biofouling using natural compounds from marine organisms. Biotechnol. Annu. Rev. 2000, 6, 221.

(8) Otani, M.; Oumi, T.; Uwai, S.; Hanyuda, T.; Prabowo, R.; Yamaguchi, T.; Kawai, H. Occurrence and diversity of barnacles on international ships visiting Osaka Bay, Japan, and the risk of their introduction. Biofouling 2007, 23, 277.

(9) Costello, M.; Grant, A.; Davies, I.; Cecchini, S.; Papoutsoglou, S.; Quigley, D.; Saroglia, M. The control of chemicals used in aquaculture in Europe. J. Appl. Ichthyol. 2001, 17, 173.

(10) Voulvoulis, N.; Scrimshaw, M.; Lester, J. Comparative environmental assessment of biocides used in antifouling paints. Chemosphere 2002, 47, 789.

(11) Fitridge, I.; Dempster, T.; Guenther, J.; de Nys, R. The impact and control of biofouling in marine aquaculture: a review. Biofouling 2012, 28, 649.

(12) Harder, T.; Lau, S.; Dobretsov, S.; Fang, T.; Qian, P. A distinctive epibiotic bacterial community on the soft coral Dendronephthya sp. and antibacterial activity of coral tissue extracts suggest a chemical mechanism against bacterial epibiosis. FEMS Microbiol. Ecol. 2003, 43, 337.

(13) Tsoukatou, M.; Maréchal, J.; Hellio, C.; Novakovic, I.; Srdan, T.; Sladic, D.; Gasic, M.; Clare, A.; Vagias, C.; Roussis, V. Evaluation of the activity of the sponge metabolites avarol and avarone and their synthetic derivatives against fouling micro- and macroorganisms. Molecules 2007, 12, 1022.

(14) Dobretsov, S.; Dahms, H.; Qian, P. Inhibition of biofouling by marine microorganisms and their metabolites. Biofouling 2006, 22, 43.

(15) Blustein, G.; Pérez, M.; García, M.; Stupak, M.; Cerruti, C. Reversible effect of potassium sorbate on Balanus amphitrite larvae. Potential use as antifoulant. Biofouling 2009, 25, 573.

(16) Xu, Y.; Li, H.; Li, X.; Xiao, X.; Qian, P. Inhibitory effects of a branched-chain fatty acid on larval settlement of the polychaete Hydroides elegans. Mar. Biotechnol. 2009, 11, 495.

(17) García-Matucheski, S.; Muniain, C.; Cutignano, A.; Cimino, G.; Faimali, M.; Piazza, V.; Aristizabal, E.; Fontana, A. Renillenoic acids: Feeding deterrence and antifouling properties of conjugated fatty acids in Patagonian sea pen. J. Exp. Mar. Biol. Ecol. 2012, 416-417, 208.

(18) Parsons, J.; Yao, J.; Frank, M.; Jackson, P.; Rock, C. Membrane disruption by antimicrobial fatty acids releases low-molecular-weight proteins from Staphylococcus aureus. J. Bacteriol. 2012, 194, 5294.

(19) Plumridge, A.; Stratford, M.; Lowe, K.; Archer, D. The weakacid preservative sorbic acid is decarboxylated and detoxified by a phenylacrylic acid decarboxylase, PadA1, in the spoilage mold Aspergillus niger. Appl. Environ. Microbiol. 2008, 74, 550.

(20) Schnell, S.; Wondrak, C.; Wahl, G.; Schink, B. Anaerobic degradation of sorbic acid by sulfate-reducing and fermenting bacteria: pentanone- 2 and isopentanone- 2 as by products. Biodegradation 1991, 2,33 .

(21) Jämsä, S.; Mahlberg, R.; Holopainen, U.; Ropponen, J.; Savolainen, A.; Ritschkoff, A. Slow release of a biocidal agent from polymeric microcapsules for preventing biodeterioration. Prog. Org. Coat. 2013, 76, 269.

(22) Vetere, V.; Pérez, M.; García, M.; Deyá, M.; Stupak, M.; del Amo, B. A non-toxic antifouling compounds for marine paints. Surf. Coat. Int. 1999, 82, 586.

(23) Rittschof, D.; Clare, A.; Gerhart, D.; Mary, A.; Bonaventura, J.. Barnacle in vitro assays for biologically active substances: toxicity and 
settlement inhibition assays using mass cultured Balanus amphitrite Darwin. Biofouling 1992, 6, 115.

(24) Pérez, M.; García, M.; Stupak, M. Studies on biofouling at Mar del Plata harbor. Monthly settlement of calcareous species along a year. CIDEPINT-Anales 1997-98, 199.

(25) Henrikson, A.; Pawlik, J. Seasonal variation in biofouling of gels containing extracts of marine organisms. Biofouling 1998, 12, 245.

(26) Foster, M.; Harrold, C.; Hardin, D. Points versus photo quadrat estimates of the cover of sessile marine organisms. J. Exp. Mar. Biol. Ecol. 1991, 146, 193.

(27) Yebra, D.; Kiil, S.; Dam-Johansen, K.; Weinell, C. Reaction rate estimation of controlled-release antifouling paint binders: Rosin-based systems. Prog. Org. Coat. 2005, 53, 256.

(28) Shapiro, S.; Wilk, M. An analysis of variance test for normality (complete samples). Biometrika 1965, 52, 591.

(29) Pérez, M.; Blustein, G.; García, M.; del Amo, B.; Stupak, M. Cupric tannate: a low copper content antifouling pigment. Prog. Org. Coat. 2006, 55, 311.

(30) Blustein, G.; Di Sarli, A.; Jaén, J.; Romagnoli, R.; del Amo, B. Study of iron benzoate as a novel steel corrosion inhibitor pigment for protective paint films. Corros. Sci. 2007, 49, 4202.

(31) Blustein, G.; Romagnoli, R.; Jaén, J.; Di Sarli, A.; del Amo, B. Aluminum basic benzoate-based coatings: evaluation of anticorrosion properties by electrochemical impedance spectroscopy and accelerated tests. Corrosion, NACE 2007, 63, 899.

(32) Pérez, M.; García, M.; Vetere, V.; Deyá, M.; del Amo, B.; Stupak, M. Benzoates: a new approach to non-toxic marine fouling control. Pigm. Resin Technol. 2001, 30, 34.

(33) del Amo, B.; Blustein, G.; Pérez, M.; García, M.; Deyá, M.; Stupak, M.; Romagnoli, R. A multipurpose compound for protective coatings. Colloids Surf. A 2008, 324, 58.

(34) Vetere, V.; Pérez, M.; Romagnoli, R.; Stupak, M.; del Amo, B. Solubility and toxic effect of the cuprous thiocyanate antifouling. $J$. Coat. Technol. 1997, 69, 39.

(35) Göransson, U.; Sjögren, M.; Svangard, E.; Claeson, P.; Bohlin, L. Reversible antifouling effect of the cyclotide cycloviolacin $\mathrm{O}_{2}$ against barnacles. J. Nat. Prod. 2004, 67, 1287.

(36) Da Gama, B.; Pereira, R.; Soares, A.; Teixeira, V.; YoneshigueValentin, Y. Is the mussel test a good indicator of antifouling activity? A comparison between laboratory and field assays. Biofouling 2003, 19, 161.

(37) Pranoto, Y.; Rakshit, S.; Salokhe, V. Enhancing antimicrobial activity of chitosan films by incorporating garlic oil, potassium sorbate and nisin. LWT-Food Sci. Technol. 2005, 38, 859.

(38) López, O.; Giannuzzi, L.; Zaritzky, N.; García, A. Potassium sorbate controlled release from corn starch films. Mater. Sci. Eng., C 2013, 33, 1583.

(39) Weng, Y.; Chen, M.; Chen, W. Antimicrobial food packaging materials from poly(ethylene-co-methacrylic acid). LWT-Food Sci. Technol. 1999, 32, 191.

(40) Uz, M.; Alsoy Altınkaya, S. Development of mono and multilayer antimicrobial food packaging materials for controlled release of potassium sorbate. LWT-Food Sci. Technol. 2011, 44, 2302.

(41) Alifragis, J.; Rizos, A.; Tsatsakis, A.; Tzatzarakis, M.; Shtilman, M. New polymeric systems with controlled release action: a light scattering investigation. J. Non-Cryst. Solids 2002, 307-310, 882.

(42) Jipa, I.; Stoica-Guzun, A.; Stroescu, M. Controlled release of sorbic acid from bacterial cellulose based mono and multilayer antimicrobial films. LWT-Food Sci. Technol. 2012, 47, 400.

(43) Böttcher, H.; Jagota, C.; Trepte, J.; Kallies, K.; Haufe, H. Solgel composite films with controlled release of biocides. J. Controlled Release 1999, 60, 57.

(44) Harvey, H. The Chemistry and Fertility of Sea Waters; Cambridge University Press: Cambridge, U.K., 1955.

(45) Head, P. Practical Estuarine Chemistry, a Handbook; Cambridge University Press: Cambridge, U.K., 1985.

(46) Finlay, J.; Callow, M. The toxicity of alkyl amines: the effects of pH. Biofouling 1997, 11, 19.
(47) Denyer, S.; Hugo, W. Mechanisms of action of chemical biocides, their study and exploitation; Blackwell Scientific Publications: Oxford, U.K., 1991.

(48) Brown, M. H.; Booth, I. R. Acidulants and low pH. In Food preservatives; Russell, N. J., Gould, G. W., Eds.; Blackie: Glasgow, U.K.. 1991; pp 22-43.

(49) Stratford, M.; Anslow, P. Evidence that sorbic acid does not inhibit yeast as a classic 'weak acid preservative'. Lett. Appl. Microbiol. 1998, 27, 203.

(50) Pawlik, J.; Faulkner, D. Specific free fatty acids induce larval settlement and metamorphosis of the reef-building tube worm Phragmatopoma californica (Fewkes). J. Exp. Mar. Biol. Ecol. 1986, 102, 301.

(51) Biggers, W.; Laufer, H. Settlement and metamorphosis of Capitella larvae induced by juvenile hormone-active compounds is mediated by protein kinase C and ion channels. Biol. Bull. 1999, 196, 187. 